\title{
España ante la Revolución Industrial 4.0: mercado laboral y formación
}

\author{
Spain in the Face of the 4.0 Industrial \\ Revolution: Labor Market and Training
}

\author{
Álvaro Choi ${ }^{1}$ \\ Universidad de Barcelona (España)
}

ORCID: https://orcid.org/0000-0003-3394-0181

Recibido: 14-06-2021

Aceptado: 23-06-2021

\section{Resumen}

Los procesos de robotización e introducción de inteligencia artificial asociados a la Revolución Industrial 4.0 implican cambios económicos y sociales. En este artículo se analizan sus implicaciones para el mercado laboral español, discutiéndose la existencia de posibles desajustes, presentes o futuros, entre la oferta y la demanda de trabajadores. Por ello se analiza, por un lado, la evolución reciente de la estructura productiva española y, por otro, la oferta laboral. Más concretamente, se presta especial atención al nivel educativo y de competencias de los trabajadores, ya que resultan centrales en la definición de los perfiles profesionales generados como consecuencia de la digitalización y automatización de la economía. Algunas de las fortalezas y debilidades, de la estructura formativa de la población española son discutidas a continuación. La Revolución Industrial 4.0 genera nuevas oportunidades para los trabajadores con mayor nivel formativo

\footnotetext{
${ }^{1}$ (alvarochoi@ub.edu). Profesor agregado en la Universidad de Barcelona e investigador del Grupo Interdisciplinar de Políticas Educativas (GIPE). Doctor en Economía por la Universidad de Barcelona, sus áreas de investigación son la Economía de la Educación, la Economía Pública y la Evaluación de Políticas Públicas. Ha participado en diversos proyectos competitivos de investigación. Ha sido Thomas J. Alexander Fellow de la OCDE y Honorary Research Associate de UCL-Institute of Education. Entre sus publicaciones caben mencionar: Borgonovi, F., Choi, Á., \& Paccagnella, M. (2021). The evolution of gender gaps in numeracy and literacy between childhood and young adulthood. Economics of Education Review, 82, 102119; Choi, Á., Guio, J., \& Escardíbul, J. O. (2020). The challenge of mapping overeducation and overskilling across countries: a critical approach using PIAAC. Compare: A Journal of Comparative and International Education, 50(2), 237-256; Choi, Á., Gil, M., Mediavilla, M., \& Valbuena, J. (2018). The evolution of educational inequalities in Spain: dynamic evidence from repeated cross-sections. Social Indicators Research, 138(3), 853-872.
} 
y elevadas competencias digitales, financieras o en áreas STEM. Por el contrario, los trabajadores de edad más avanzada y los trabajadores con un menor nivel formativo aparecen entre los colectivos más vulnerables. La introducción de reformas en el sistema formativo resulta urgente no solamente para consolidar el proceso de transformación económica, sino para minimizar también los costes sociales asociados a la Revolución Industrial 4.0.

Palabras-clave: revolución industrial, inteligencia artificial, automatización, capital humano; empleo.

\section{Abstract}

The process of robotization and the introduction of artificial intelligence which are linked to the 4.0 Industrial Revolution imply economic and social changes. This article analyzes its implications for the Spanish labor market, discussing the existence of possible imbalances, present or future, between the supply and demand of workers. For this reason this study assesses, on the one hand, the recent evolution of the Spanish productive structure and, on the other, the labor supply. More specifically, special attention is paid to the educational level and skills of the workers, since they are central in the definition of the professional profiles generated as a result of the digitization and automation of the economy. A number of the strengths and weaknesses of the formative structure of the Spanish population are then discussed. The 4.0 Industrial Revolution creates new opportunities for workers with a higher level of training and high digital, financial or STEM skills. On the contrary, older workers and workers with a lower level of training appear among the most vulnerable groups. The introduction of reforms in the training system is urgent not only to consolidate the process of economic transformation, but also to minimize the social costs associated with the 4.0 Industrial Revolution.

Keywords: Industrial Revolution, Artificial Intelligence, Automation, Human Capital, Employment.

\section{Introducción}

La Revolución Industrial 4.0 consiste en la introducción acelerada en la actividad productiva, desde mediados de la década de 2010, de sistemas de inteligencia artificial y procesos de automatización e interconexión del trabajo. En esta revolución juegan un papel central la gestión y explotación de datos, la interacción entre el mundo físico y el digital (physical-to digital-to physical), el aprendizaje artificial autónomo y la introducción de robots capaces de aprender y de desempeñar tareas cada vez más complejas. 
Esta revolución no solo abre la puerta al desarrollo de nuevos bienes y servicios, sino que implica también nuevas formas de organización del trabajo y profundos cambios sociales (World Economic Forum, 2016). Por ejemplo, la combinación de nueva tecnología, unida a la inteligencia artificial y la transmisión de datos por redes en tiempo real, permite que el propietario de un coche pase de ser consumidor de energía a prosumidor. O piénsese en las cibermonedas, basadas en la explotación de algoritmos. O en los bots que controlan buena parte de los fondos manejados en los mercados financieros internacionales. $\mathrm{O}$ en el ajuste de las ofertas publicitarias de bienes y servicios individualizadas a cada consumidor, gracias a la explotación de big data. Todos ellos son ejemplos de cambios acaecidos durante los últimos años, vinculados a la Revolución Industrial 4.0, y que han generado nuevas oportunidades laborales.

Ahora bien, todo proceso disruptivo conlleva oportunidades para algunas personas, pero también supone una amenaza para otros colectivos (OCDE, 2019). La introducción de tecnologías y formas novedosas de organización del trabajo implica la destrucción o transformación de anteriores puestos de trabajo. Las personas que no dispongan de las competencias necesarias para adaptarse a estos cambios corren un elevado riesgo de verse excluidas en el nuevo sistema productivo. Es más, en el nivel macro, una muy elevada proporción de personas carente de las competencias demandas por la Revolución Industrial 4.0 podría limitar seriamente su implementación en un país o bien condicionar el carácter inclusivo de dicha revolución. Por tanto, la valoración del efecto agregado dependerá en buena medida del balance entre puestos de trabajo creados y puestos destruidos, y sus características. Este balance, sin embargo, resulta difícil de realizar ex ante (Arnzt et al., 2017).

World Economic Forum (2016) empleaba un plazo de cinco años para la realización de predicciones de los efectos de la Revolución 4.0 sobre el mercado laboral y pronosticaba que, durante ese mismo período de tiempo, se aceleraría la restructuración industrial y la reconfiguración de los modelos de negocio, aumentando las necesidades de competencias. Por ello, este resulta un momento óptimo para valorar los efectos iniciales de la Revolución Industrial 4.0 en el mercado laboral español e identificar tendencias y desajustes entre su tejido productivo y la composición de su población activa.

El objetivo de este artículo es analizar el efecto inicial de la Revolución Industrial 4.0 sobre el mercado laboral español y ponerlo en contacto con la estructura formativa de la oferta laboral. Ello permite identificar fortalezas y debilidades de la estructura formativa de España y su capacidad para acelerar o condicionar la implementación exitosa de la Revolución Industrial 4.0. Para ello, el artículo se estructura de la siguiente manera: el capítulo 2 resume brevemente los distintos efectos potenciales de la Revolución Industrial 4.0 
sobre los mercados laborales; el capítulo 3 describe la evolución reciente del mercado laboral español; y el capítulo 4 revisa la dotación educativa de la población activa. El capítulo 5 cierra el artículo con una serie de consideraciones y recomendaciones para conseguir una transición exitosa e inclusiva.

\section{Revolución Industrial 4.0 y mercado laboral: ¿amenaza u oportunidad?}

Las transformaciones socioeconómicas asociadas a la Revolución Industrial 4.0 son diversas y profundas. Ahora bien, a efectos de este artículo, nos centraremos en su impacto sobre el mercado laboral y, más en concreto, sobre los distintos perfiles de trabajadores. La cuarta revolución industrial incluye, entre otros avances, la aplicación de biotecnología, desarrollos en genética, la utilización de algoritmos matemáticos, la nanotecnología y la creación de dispositivos que conectan el mundo real con el mundo digital. Estos avances quedan englobados, en mayor o menor grado, dentro de los conceptos de robotización o automatización y la inteligencia artificial (IA). Tanto la robotización como la IA afectan a los mercados de trabajo y al tipo de perfiles demandados. No obstante, no existe consenso acerca de cuál será el efecto concreto de la robotización y la IA sobre el saldo neto de puestos de trabajo (empleos creados menos empleos destruidos) y las características de esos puestos. Así, Frey y Osborne (2017) argumentan que el saldo neto agregado será negativo, mientras que Autor y Salomons (2017) opinan lo contrario. De hecho, el efecto de la robotización y la IA pueden ser distintos y, para cada uno de ellos, depender a su vez del tipo de tecnología concreta (Mokyr, 2018). Es más, las innovaciones consistentes en aumentar la gama de productos tienden a expandir la demanda de trabajo, mientras que las innovaciones organizativas, de proceso, suelen reducirla (Vivarelli, 2014).

La robotización del trabajo -sustitución de trabajadores por máquinases un proceso que se viene produciendo desde el siglo XVIII. Sin embargo, el proceso de automatización observado a lo largo de la última década tiene unas características específicas: 1) mayor flexibilidad y capacidad de individualización del trabajo; 2) capacidad multitarea; y 3) capacidad de programación y reajuste autónomo de las máquinas. Ello permite pasar de la producción en serie estandarizada a la producción masiva individualizada. Las tareas más fácilmente automatizables son aquellas que consisten en tareas rutinarias (Boughin et al., 2017) y el ritmo de sustitución de trabajo por máquinas en los diversos sectores queda condicionado por la facilidad de robotización de las tareas (Sachs et al., 2015) y el coste relativo respecto al mantenimiento del factor trabajo (Decker et al., 2017). Resulta importante a su vez añadir que 
el proceso de automatización asociado a la Revolución Industrial 4.0 no se ha limitado a la sustitución de tareas rutinarias (típicamente desarrolladas por trabajadores con reducidos niveles formativos), sino que ha complementado las labores de trabajadores con elevados niveles de cualificación (Gibbs, 2017).

Entre los autores más optimistas de los efectos de la robotización se encuentran Acemoglu y Restrepo (2020), Autor y Salomons (2017), y Dauth et al. (2017), quienes exponen que, como consecuencia del incremento en la productividad asociado a la automatización de los procesos de producción, aumentará el consumo y la renta de los ciudadanos. Ello llevará a un crecimiento en la demanda agregada que derivará en un aumento o, como mínimo, el mantenimiento de un nivel constante de empleo ofrecido. Todos ellos indican que sí existirá una redistribución de los puestos entre sectores. En los sectores más afectados por la automatización caerá el volumen total de trabajadores pero, los nuevos perfiles profesionales creados en dichos sectores, contarán con buenas condiciones de trabajo, acordes con los elevados niveles de cualificación demandados. En cambio, las personas con menores niveles de cualificación y que trabajan sectores con una baja productividad verán perjudicadas sus condiciones laborales (Hutter y Weber, 2017). Nótese que el proceso anterior puede conducir a una mayor desigualdad de ingresos entre trabajadores (Berg et al., 2018), si bien Caselli y Manning (2019) matizan que el nivel de desigualdad salarial generado por el proceso de robotización dependerá principalmente del precio relativo entre los bienes de inversión y los bienes de consumo.

En cualquier caso, los autores citados hasta el momento sí coinciden en la existencia de costes de transición en el corto plazo y en el hecho de que los puestos de trabajo creados a raíz de la robotización en la Revolución Industrial 4.0 requieren un mayor nivel de cualificación y de habilidades (CEDEFOP, 2018). Tanto Eichhorst (2015) como Levy (2018) explican que, cuanto más progresivo sea el proceso, mayor será la capacidad de readaptación de los trabajadores y de diseñar medidas compensatorias y de apoyo a los "perdedores" en el proceso de implementación de robotización de la actividad económica. Sachs et al. (2015) apuestan por el diseño de políticas redistributivas de rentas mientras que Schmidtpeter y Winter-Ebmer (2018) proponen políticas activas de empleo para facilitar que las personas menos cualificadas puedan reincorporarse al mercado laboral a la mayor brevedad posible. Pese a todo, Autor y Salomons (2017) advierten del riesgo de que haya personas con un bajo nivel de cualificación, procedentes de los sectores industrial y primario, que no consigan adaptarse a los puestos de nueva creación ni a los disponibles, principalmente en el sector servicios, ya que los servicios personales, difíciles de robotizar, exigen elevados niveles de cualificación. 
La IA es la parte de la informática que desarrolla algoritmos para la obtención de máquinas capaces de tomar decisiones "inteligentes". Las áreas en las que la IA cuenta con una mayor presencia son las telecomunicaciones, las finanzas y el sector de la automoción (Bughin et al., 2017). La introducción de IA en la actividad económica también tiene efectos sobre los niveles de ocupación y los salarios ${ }^{2}$. Aghion et al. (2019) y Morikawa (2017) exponen que una de las consecuencias de la IA será un aumento en la demanda de trabajadores altamente cualificados, trabajadores que deben disponer de competencias flexibles. Ambos señalan que parte de los trabajos - principalmente, servicios personalesno se verán afectados por la IA, al resultar de difícil automatización -en una nueva versión de la "enfermedad de Baumol"-. El impacto sobre los salarios de los trabajadores cualificados dependerá de su abundancia relativa respecto a los puestos creados (Cowen, 2019) y si la IA resulta complementaria o sustitutiva del capital humano (Raj y Seamans, 2019). Coincidiendo con este último punto, Brynjolfsson y Mitchell (2017) añaden que los efectos de la IA sobre el trabajo dependerán también de la elasticidad precio de las tareas a sustituir por IA; de la elasticidad renta de los bienes y servicios; del grado de complementariedad entre competencias humanas específicas y la IA; de la velocidad en la reestructuración de los procesos productivos; y de la capacidad de adaptación de la oferta laboral a alteraciones en la demanda laboral.

Los cambios en el mercado laboral causados por la introducción de IA tienen por tanto, como sucedía con la robotización, efectos redistributivos de los ingresos. Éstos pueden venir por a través de la supresión de ciertos tipos de trabajo; la creación de nuevos perfiles profesionales; el reajuste de salarios; la acumulación de beneficios por los empresarios innovadores; y el cambio en el precio relativo del trabajo respecto al capital físico (Korinek y Stiglitz, 2019). Estos efectos tienden a incrementar la desigualdad. Cowen (2019), algo más optimista, considera que la introducción de IA abaratará el precio de los bienes de consumo, amortiguándose así el impacto negativo de la caída de ingresos de los "perdedores" de la introducción de la IA.

Los trabajos presentados hacen uso de modelos teóricos, o bien emplean datos correspondientes a EEUU, Japón o Alemania. La evidencia sobre los efectos concretos de la Revolución Industrial para el caso español resulta mucho más escasa. Doménech et al. (2018), extrapolando las previsiones de Frey y Osborne (2017), calculan que el 36\% de los puestos de trabajo de España corren un elevado riesgo de automatización. González-Páramo (2018) expone que, como consecuencia de la Revolución Industrial 4.0, el empleo en España cada vez será menos rutinario; más fraccionado -apareciendo nuevas modalidades colaborativas y plataformas digitales-; y cambiante. Ello implicará la necesidad de disponer de trabajadores más flexibles y capaces de reinventarse, evitando la sobreespecialización para no quedar excluidos del mercado laboral.

\footnotetext{
${ }^{2}$ Lane y Saint-Martin (2021) proporcionan una excelente revisión de la literatura.
} 
Peco (2017), añade que los trabajadores españoles deberán disponer de las siguientes competencias para poderse integrar en el nuevo mercado laboral: habilidades transversales; capacidad de resolución de problemas complejos; inteligencia emocional; capacidad de tratamiento de datos; y habilidades cognitivas y procedimentales.

Choi y Calero (2018) realizaron una primera aproximación cuantitativa, concluyendo que existen fuertes indicios sobre el proceso de sustitución de trabajo no cualificado, siendo este proceso más acusado en los sectores más innovadores. Lladós-Masllorens (2019), analizando la evolución del mercado laboral español posterior a la Gran Recesión, llega a similares conclusiones. Arguye que la implementación de tecnologías intensivas en el uso de capital humano no es tan intensa en España, ya que su economía tiene una elevada dependencia de actividades rutinarias - que no repetitivas- difíciles de ser automatizadas -servicios personales, salud, hostelería-. Braña (2019) expone que la digitalización tiene dos efectos principales sobre el mercado laboral español: la caída en puestos de trabajo en los sectores más afectados por la automatización y un aumento en la polarización del empleo entre las personas con mayores y menores niveles de cualificación. De forma interesante, describe una caída en los puestos que requieren una cualificación intermedia. Finalmente, Dolado et al. (2021), centrándose en la evolución del mercado laboral post-COVID, que perjudicó especialmente a los grupos más vulnerables -jóvenes, mujeres, personas con bajos niveles educativos y contratados temporales-, describen la aceleración de las tendencias estructurales vinculadas a la Revolución Industrial 4.0 existentes antes de la pandemia: aumento de la digitalización y automatización; polarización del trabajo; crecimiento de los negocios en plataforma; y aparición de empresas "estrella". Consideran que a la Gran Recesión le seguirá la era de la Gran Reasignación del trabajo, ajustándose la oferta y demanda laboral a los cambios estructurales asociados a la Revolución Industrial 4.0 y a la Agenda Verde Europea 2050. Tal y como hacían Kuzmenko y Roienko (2017), también prevén un aumento en la desigualdad de ingresos en España y recomiendan, en la línea de Korinek y Stiglitz (2019), la articulación de medidas compensatorias para amortiguar los costes sociales de este proceso.

Por tanto, tal y como se puede apreciar, la consideración final de la Revolución Industrial 4.0 como amenaza u oportunidad para un país dependerá fundamentalmente de la interacción entre la estructura productiva y la composición de su población, así como de la capacidad de dicho país para compensar a los perdedores en el proceso de transición hacia el nuevo modelo productivo. De forma previa al análisis del ajuste de la situación formativa de la población española a los requerimientos de la Revolución Industrial 4.0, en el siguiente capítulo se expone, de forma sucinta, la evolución reciente de la estructura productiva de España. 


\section{La demanda laboral: estructura productiva de España}

La composición de la economía española ha cambiado sustancialmente durante el último cuarto de siglo. Durante dicho período, todos los sectores han ido perdiendo peso relativo sobre el PIB, justo lo contrario a lo observado para el sector servicios que, en el año 2021, representaba al $74 \%$ del valor añadido bruto de la economía española (figura 1). En términos de empleo, casi 8 de cada 10 personas se encontraban ocupadas en el sector servicios en el año 2021, frente al $65 \%$ del año 1996. Se observa a su vez que los sectores más intensivos en la utilización del factor trabajo son el sector primario, la construcción y los servicios.

Figura 1. Peso sobre el valor añadido bruto y en términos de empleo (entre paréntesis) por sectores productivos, porcentajes. España, 1996-2021.

\begin{tabular}{lrrrrrr} 
& $\mathbf{1 9 9 6}$ & $\mathbf{2 0 0 1}$ & $\mathbf{2 0 0 6}$ & $\mathbf{2 0 1 1}$ & $\mathbf{2 0 1 6}$ & \multicolumn{1}{c}{$\mathbf{2 0 2 1}$} \\
Primario & & 3.7 & 2.5 & & 2.8 & 2.7 \\
& $4.3(7.6)$ & $(6.0)$ & $(4.5)$ & $2.4(4.2)$ & $(4.2)$ & $(3.7)$ \\
Construcción & & 10.1 & 11.7 & & 5.5 & 5.8 \\
& $8.7(8.7)$ & $(11.0)$ & $(12.5)$ & $7.5(7.9)$ & $(5.7)$ & $(6.7)$ \\
Industria & 23.6 & 22.0 & 19.6 & 17.9 & 17.4 & 17.9 \\
& $(18.7)$ & $(18.5)$ & $(14.7)$ & $(12.1)$ & $(11.3)$ & $(10.6)$ \\
Servicios & 63.4 & 64.2 & 66.1 & 72.3 & 74.2 & 73.7 \\
& $(64.9)$ & $(64.4)$ & $(68.4)$ & $(75.8)$ & $(78.8)$ & $(78.9)$ \\
TOTAL & 100.0 & 100 & 100 & 100 & 100 & 100
\end{tabular}

Fuente: INE.

Nota: Datos correspondientes al primer trimestre del año correspondiente.

La información presentada en la figura 1 es a nivel agregado y abarca un período muy superior al de interés para este artículo. Por otro lado, los datos correspondientes al año 2021 están afectados por el shock de la COVID-19, por lo que conviene realizar un análisis más detallado, por sectores, para el período temporal en el que se ha empezado a desarrollar la Revolución Industrial 4.0.

La figura 2 muestra la evolución en el número de empleados por áreas de actividad, durante el período 2015-2021. Se toma el año 2015 como año base y se calcula el crecimiento respecto a dicho año. Al tratarse de datos correspondientes al primer trimestre de cada año, el año de 2020 resulta de especial interés, al recoger la situación justamente previa a la pandemia. Hará falta una mayor perspectiva temporal para poder observar si los cambios de tendencia son temporales o permanentes. El número total de ocupados en España creció aproximadamente un 13\% entre 2015 y 2020. Dejando a un lado a los empleados en organismos internacionales, cuyas estadísticas resultan muy 
sensibles al tamaño muestral, los sectores en los que creció de forma más intensa la ocupación fueron los sectores de información y comunicaciones, actividades inmobiliarias, construcción y transporte y almacenamiento. Por el contrario, en los sectores financiero y energético no solamente no se creó ocupación, sino que se destruyó. Esta última constatación parece coherente con la predicción de Bughin et al. (2017), quienes identificaban a estos dos sectores y la automoción como los más susceptibles de ser automatizados y digitalizados. Llama también la atención la congelación en la contratación pública, así como la recuperación de la ocupación en la construcción y el aumento de la contratación en servicios como la educación y servicios personales. Hostelería y servicios recreativos también ganaron peso en términos de ocupación, si bien la tabla muestra una intensa destrucción de empleo durante la crisis COVID-19.

Figura 2. Evolución del número de ocupados por áreas de actividad CNAE, base 2015=100. España, 2015-2021.

\begin{tabular}{|c|c|c|c|c|c|c|c|}
\hline & 2015 & 2016 & 2017 & 2018 & 2019 & 2020 & 2021 \\
\hline $\begin{array}{l}\text { A Agricultura, ganadería, } \\
\text { silvicultura y pesca }\end{array}$ & 100 & 108 & 118 & 116 & 117 & 109 & 111 \\
\hline B Industrias extractivas & 100 & 105 & 126 & 121 & 113 & 112 & 115 \\
\hline $\mathrm{C}$ Industria manufacturera & 100 & 103 & 106 & 111 & 112 & 115 & 108 \\
\hline $\begin{array}{l}\text { D Suministro de energía } \\
\text { eléctrica, gas, vapor y } \\
\text { aire acondicionado }\end{array}$ & 100 & 85 & 87 & 74 & 91 & 86 & 94 \\
\hline $\begin{array}{l}\text { E Suministro de agua, } \\
\text { actividades de saneamiento, } \\
\text { gestión de residuos y } \\
\text { descontaminación }\end{array}$ & 100 & 95 & 97 & 113 & 107 & 113 & 118 \\
\hline F Construcción & 100 & 97 & 102 & 109 & 121 & 120 & 119 \\
\hline $\begin{array}{l}\text { G Comercio al por } \\
\text { mayor y al por menor; } \\
\text { reparación de vehículos } \\
\text { de motor y motocicletas }\end{array}$ & 100 & 100 & 103 & 101 & 104 & 106 & 102 \\
\hline $\begin{array}{l}\text { H Transporte y } \\
\text { almacenamiento }\end{array}$ & 100 & 110 & 113 & 116 & 124 & 123 & 122 \\
\hline I Hostelería & 100 & 111 & 110 & 115 & 117 & 116 & 91 \\
\hline $\begin{array}{l}\mathrm{J} \text { Información y } \\
\text { comunicaciones }\end{array}$ & 100 & 109 & 109 & 115 & 114 & 120 & 123 \\
\hline $\begin{array}{l}\text { K Actividades financieras } \\
\text { y de seguros }\end{array}$ & 100 & 104 & 101 & 102 & 95 & 97 & 109 \\
\hline L Actividades inmobiliarias & 100 & 108 & 123 & 133 & 157 & 148 & 160 \\
\hline
\end{tabular}




\begin{tabular}{|c|c|c|c|c|c|c|c|}
\hline $\begin{array}{l}\text { M Actividades } \\
\text { profesionales, } \\
\text { científicas y técnicas }\end{array}$ & 100 & 101 & 109 & 110 & 114 & 118 & 123 \\
\hline $\begin{array}{l}\text { N Actividades } \\
\text { administrativas y } \\
\text { servicios auxiliares }\end{array}$ & 100 & 104 & 104 & 101 & 109 & 114 & 110 \\
\hline $\begin{array}{l}\text { O Administración Pública } \\
\text { y defensa; Seguridad } \\
\text { Social obligatoria }\end{array}$ & 100 & 95 & 94 & 99 & 100 & 101 & 102 \\
\hline P Educación & 100 & 110 & 110 & 113 & 122 & 118 & 123 \\
\hline $\begin{array}{l}\text { Q Actividades sanitarias } \\
\text { y de servicios sociales }\end{array}$ & 100 & 104 & 108 & 111 & 114 & 121 & 128 \\
\hline $\begin{array}{l}\text { R Actividades artísticas, } \\
\text { recreativas y de } \\
\text { entretenimiento }\end{array}$ & 100 & 106 & 106 & 108 & 114 & 116 & 95 \\
\hline S Otros servicios & 100 & 107 & 107 & 113 & 110 & 116 & 111 \\
\hline $\begin{array}{l}\text { T Actividades de los } \\
\text { hogares como empleadores } \\
\text { de personal doméstico; } \\
\text { actividades de los hogares } \\
\text { como productores de bienes } \\
\text { y servicios para uso propio }\end{array}$ & 100 & 97 & 99 & 100 & 99 & 91 & 87 \\
\hline $\begin{array}{l}\text { U Actividades de } \\
\text { organizaciones } \\
\text { y organismos } \\
\text { extraterritoriales }\end{array}$ & 100 & 100 & 131 & 69 & 146 & 262 & 292 \\
\hline Total & 100 & 103 & 106 & 108 & 112 & 113 & 110 \\
\hline
\end{tabular}

Fuente: INE.

Nota: Datos correspondientes al primer trimestre del año correspondiente.

Raj y Seamans (2019) advertían que la demostración de la sustituibilidad o complementariedad entre trabajadores, máquinas e IA requiere de la utilización de datos micro a nivel de empresa, y Arnzt et al. (2017) exponen que el empleo de información a nivel sectorial puede llevar a la sobreestimación de los efectos de la automatización sobre los niveles de ocupación. En cualquier caso, las figuras 3 y 4 aportan información adicional, siguiendo una aproximación muy similar a la empleada por Choi y Calero (2018), acerca de la evolución del empleo por sectores y la posible vinculación de aquélla a la Revolución Industrial 4.0. La figura 3 complementa la información de la figura 2 y analiza si, a nivel agregado, la creación/destrucción de empleo se ha comportado de forma distinta en los sectores más innovadores. 
Figura 3. Evolución de los ocupados por sectores productivos, por intensidad de innovación tecnológica. España, 2015-2021 (2015=100).

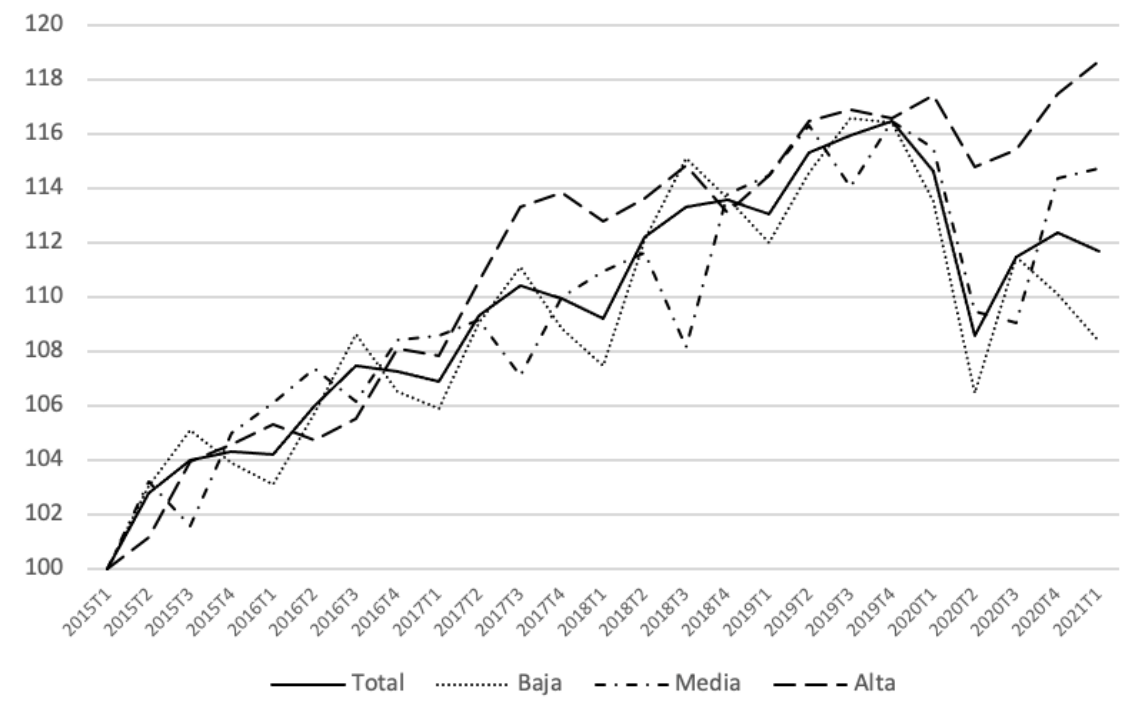

Fuente: Elaborado a partir de Encuesta sobre la Innovación en las Empresas y EPA.

La clasificación por "intensidad de innovación" de la figura 3 se ha realizado siguiendo la metodología empleada por Choi y Calero (2018). Así, se explota información correspondiente a diversas olas de la Encuesta sobre la Innovación de las Empresas del Instituto Nacional de Estadística. Esta encuesta considera tanto las innovaciones en la producción de bienes y servicios como las organizativas. El grado de intensidad de innovación se define como el porcentaje que representan los gastos en actividades de innovación tecnológica sobre la cifra total de negocios. Una vez diferenciado el grado de innovación por sectores, se agrupa a los trabajadores de dichos sectores, utilizando datos correspondientes a la Encuesta de Población Activa (trimestral, desde 2015 hasta el primer trimestre de 2021), y se procede al cálculo de la evolución de la ocupación. A modo de ejemplo, la utilización de esta definición de "intensidad de innovación" lleva a considerar a las telecomunicaciones, actividades de I+D o la industria de la automoción, como actividades con un alto nivel de intensidad innovadora; textil, metalurgia o finanzas, como actividades con un nivel medio de innovación; y actividades como la hostelería, el comercio o la construcción, como actividades con un nivel bajo de innovación ${ }^{3}$.

La evolución mostrada por la figura 3 queda claramente partida por la pandemia COVID-19. El período que va de 2015 hasta el final de 2019 es de creación de ocupación. Ésta resultó algo superior para los sectores con un grado elevado de

\footnotetext{
${ }^{3}$ Puede consultarse una descripción más detallada de la metodología en Choi y Calero (2018).
} 
intensidad innovadora. Pueden estar contrarrestándose aquí dos factores: por un lado, se trata de las actividades más dinámicas $-\mathrm{y}$, por tanto, aumenta la demanda de trabajadores- $\mathrm{y}$, por otro lado, son las empresas donde está produciéndose de forma más acelerada la sustitución de trabajadores como consecuencia de la introducción de procesos de automatización y digitalización. Ahora bien, a partir del tercer trimestre del año 2019 se produce un claro cambio: una brusca caída del empleo en las actividades de innovación media y baja, caída que resulta más suave en las empresas más innovadoras. Adicionalmente se observa que, desde mediados de 2020, se produce un proceso de recuperación de empleo en los sectores de intensidad innovadora media y alta, pero sigue destruyéndose empleo en los sectores de innovación baja, incluso considerando el efecto amortiguador de las herramientas articuladas por el sector público - principalmente, los expedientes de regulación temporal del empleo-. La crisis generada por la pandemia puede haber acelerado el proceso de ajuste de la economía española a la Revolución Industrial 4.0.

En la figura 3 no aparece reflejada la evolución de la ocupación en el sector público, ni el empleo del hogar, ya que ninguna de estas actividades queda recogida en la Encuesta sobre la Innovacion de las Empresas. Vale la pena mencionar no obstante que, durante el período analizado, el empleo público creció muy levemente mientras que, el empleo del hogar, cayó de forma importante (un 12,5\%, durante el período considerado).

La figura 4 reproduce el análisis de la figura 3, para el mismo período, pero no emplea el "grado de innovación" de los sectores, sino que se centra en el seguimiento específico de las áreas de actividad señaladas por Bughin et al. (2017) como las más propensas a ser afectadas por los procesos de automatización: la automoción, las finanzas y las telecomunicaciones e información. Estas tres ramas de actividad siguen trayectorias muy diferentes. La ocupación en el sector de la automoción evolucionó de forma muy similar a la de la ocupación media en España, aunque la ocupación empieza a caer antes de la crisis COVID-19, y se recupera a partir de 2020. Nuevamente, aquí pueden estar contrarrestándose la sustitución de trabajadores por máquinas e IA, por la creación de nuevos perfiles laborales.

En el sector financiero se observa un proceso de destrucción de empleo durante el período 2015-2020, si bien se da una intensa recuperación a finales del período considerado. Se trata de un sector en pleno proceso de reestructuración y muy afectado por la implementación de IA. Resultará de interés analizar, en los próximos años, el perfil de los nuevos empleados de un sector que ha alterado claramente su modelo de negocio como consecuencia de la Revolución Industrial 4.0.

Finalmente, en el área de telecomunicaciones e información, se observa un aumento constante en la ocupación a lo largo del período, siendo un sector muy dinámico y relativamente poco afectado, en términos de desempleo, por la crisis económica. El análisis de estos tres sectores potencialmente muy afectados por la Revolución Industrial 4.0 muestra que, efectivamente, resulta 
difícil pronosticar el impacto final de la digitalización y automatización sobre el volumen total de trabajo.

Figura 4. Evolución de los ocupados en automoción, finanzas y telecomunicaciones e información (2015 T1=100). España, 2015-2021.

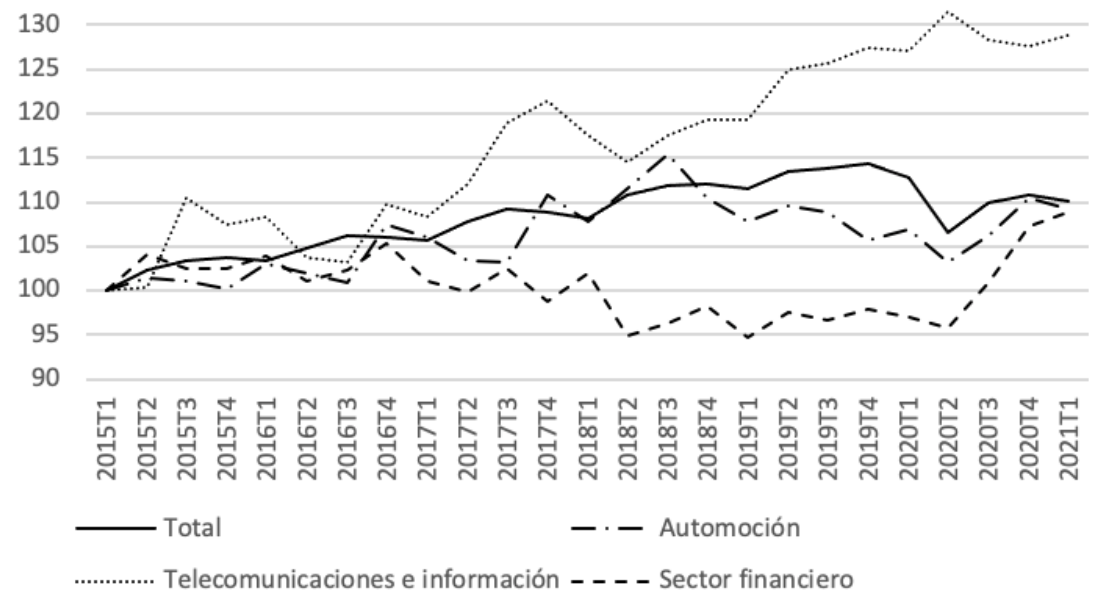

Fuente: Elaboración propia a partir de EPA.

Nota: Datos trimestrales. Códigos CNAE: automoción, 29 y 30; finanzas, 64, 65 y 66; telecomunicaciones e información, 61 y 62 .

En cualquier caso, y aun reconociendo que resultaría necesario disponer de información muy detallada a nivel de empresa para poder evaluar con mayor precisión el impacto de la digitalización y automatización sobre el número de ocupados en actividades concretas, el análisis de los cambios en la composición educativa de los ocupados en cada sector ofrece indicios acerca de qué tipo de perfiles se están creando y destruyendo en cada uno de ellos. La figura 5 presenta la distribución de trabajadores, por ramas de actividad y nivel educativo en el año 2020 y, también, la evolución de dicha distribución entre 2015 y 2020. Es decir, no solo informa sobre las características educativas de los ocupados en estas actividades, sino que también indica qué perfiles han ganado peso relativo respecto al año 2015.

Los sectores con una mayor proporción de trabajadores con educación superior son finanzas y seguros, educación, información y comunicaciones, y actividades profesionales y técnicas. En el otro extremo se encuentran el sector primario, las industrias extractivas, el empleo del hogar, la restauración y hostelería, servicios administrativos y construcción. 
Figura 5. Distribución del nivel educativo de los trabajadores por ramas de actividad, en porcentajes, y variación en su composición educativa entre 20152019, y 2015-2020 $(2015=100)$.

\begin{tabular}{|c|c|c|c|c|c|c|c|}
\hline & $\begin{array}{c}\% \\
2020\end{array}$ & $\begin{array}{c}\Delta \\
15-19\end{array}$ & $\begin{array}{c}\Delta \\
15-20\end{array}$ & & $\begin{array}{c}\% \\
2020\end{array}$ & $\underset{15-19}{\Delta}$ & $\begin{array}{c}\Delta \\
15-20\end{array}$ \\
\hline \multicolumn{4}{|l|}{ España } & \multicolumn{4}{|l|}{ Finanzas y seguros } \\
\hline Hasta ESO & 29.4 & 95.1 & 90.5 & Hasta ESO & 4.2 & 95.8 & 87.5 \\
\hline Secundaria post. & 23.3 & 98.7 & 99.6 & Secundaria post. & 14.4 & 81.9 & 72.4 \\
\hline Educación superior & 47.4 & 104.3 & 107.5 & Educación superior & 81.3 & 105.0 & 108.0 \\
\hline \multicolumn{4}{|c|}{ Agricultura, silvicultura y pesca } & \multicolumn{4}{|c|}{ Actividades del sector inmobiliario } \\
\hline Hasta ESO & 71.7 & 99.2 & 99.6 & Hasta ESO & 9.8 & 123.0 & 86.7 \\
\hline Secundaria post. & 15.3 & 97.7 & 89.0 & Secundaria post. & 26.5 & 89.4 & 94.0 \\
\hline Educación superior & 13 & 109.3 & 120.4 & Educación superior & 63.7 & 100.8 & 105.5 \\
\hline \multicolumn{4}{|l|}{ Industrias extractivas } & \multicolumn{4}{|c|}{$\begin{array}{l}\text { Actividades profesionales, científicas y técni- } \\
\text { cas }\end{array}$} \\
\hline Hasta ESO & 52.5 & 101.9 & 111.2 & Hasta ESO & 4.5 & 94.0 & 90.0 \\
\hline Secundaria post. & 32.2 & 83.3 & 96.1 & Secundaria $\mathrm{p}$ & 12.8 & 100.7 & 92.1 \\
\hline Educación superior & 15.3 & 123.8 & 79.3 & Educación superior & 82.7 & 100.4 & 102.1 \\
\hline \multicolumn{4}{|l|}{ Manufacturas } & \multicolumn{4}{|c|}{ Servicios administrativos } \\
\hline Hasta ESO & 41.6 & 109.5 & 113.0 & Hasta ESO & 47.2 & 92.8 & 91.3 \\
\hline Secundaria post. & 23.8 & 99.1 & 104.4 & Secundaria post. & 25.7 & 106.6 & 106.6 \\
\hline Educación superior & 34.6 & 92.1 & 85.9 & Educación superior & 27.1 & 108.7 & 112.0 \\
\hline \multicolumn{4}{|l|}{ Electricidad y gas } & \multicolumn{4}{|c|}{$\begin{array}{l}\text { Administración pública, defensa y seguridac } \\
\text { social }\end{array}$} \\
\hline Hasta ESO & 10.1 & 127.3 & 83.5 & Hasta ESO & 15.8 & 83.0 & 84.0 \\
\hline Secundaria post. & 12.6 & 91.2 & 65.3 & Secundaria post. & 26.4 & 93.8 & 90.7 \\
\hline Educación superior & 77.3 & 97.7 & 112.7 & Educación superior & 57.8 & 109.8 & 110.9 \\
\hline \multicolumn{4}{|c|}{$\begin{array}{l}\text { Vapor y aire acondicionado, suministro agua, } \\
\text { gestión residuos }\end{array}$} & \multicolumn{4}{|l|}{ Educación } \\
\hline Hasta ESO & 43.9 & 101.5 & 93.6 & Hasta ESO & 4.5 & 105.8 & 86.5 \\
\hline Secundaria post. & 24.1 & 92.7 & 103.4 & Secundaria post. & 5.7 & 101.8 & 100.0 \\
\hline Educación superior & 32 & 103.0 & 107.4 & Educación superior & 89.8 & 99.6 & 100.8 \\
\hline \multicolumn{4}{|l|}{ Construcción } & \multicolumn{4}{|c|}{ Sanidad y servicios sociales } \\
\hline Hasta ESO & 51.3 & 98.9 & 97.3 & Hasta ESO & 12.4 & 91.7 & 85.5 \\
\hline Secundaria post. & 22.7 & 116.8 & 119.5 & Secundaria post. & 24.2 & 107.0 & 105.7 \\
\hline Educación superior & 26 & 91.2 & 91.9 & Educación superior & 63.5 & 99.5 & 101.4 \\
\hline
\end{tabular}




\begin{tabular}{|c|c|c|c|c|c|c|c|}
\hline \multicolumn{4}{|c|}{$\begin{array}{l}\text { Comercio al por mayor y minorista; reparación } \\
\text { de vehículos }\end{array}$} & \multicolumn{4}{|c|}{ Arte, entretenimiento y recreación } \\
\hline Hasta ESO & 36.1 & 95.9 & 91.4 & Hasta ESO & 22.6 & 97.4 & 84.0 \\
\hline Secundaria post. & 29.8 & 96.3 & 101.4 & Secundaria post. & 23.5 & 88.0 & 94.4 \\
\hline Educación superior & 34.1 & 108.7 & 109.6 & Educación superior & 53.9 & 107.9 & 112.1 \\
\hline \multicolumn{4}{|c|}{ Transporte y almacenamiento } & \multicolumn{4}{|c|}{ Otras actividades de servicios } \\
\hline Hasta ESO & 39.8 & 99.5 & 98.3 & Hasta ESO & 26.4 & 85.8 & 85.2 \\
\hline Secundaria post. & 27.3 & 95.0 & 90.1 & $\begin{array}{l}\text { Secundaria } \\
\text { postobligatoria }\end{array}$ & 30.3 & 106.5 & 103.8 \\
\hline Educación superior & 32.8 & 105.8 & 112.3 & Educación superior & 43.3 & 106.3 & 108.8 \\
\hline \multicolumn{4}{|c|}{ Restauración y hostelería } & \multicolumn{4}{|l|}{ Actividades del hogar } \\
\hline Hasta ESO & 45 & 94.3 & 91.6 & Hasta ESO & 54.7 & 95.1 & 95.1 \\
\hline Secundaria post. & 31.8 & 101.7 & 108.5 & Secundaria post. & 31.1 & 104.8 & 105.8 \\
\hline Educación superior & 23.2 & 110.6 & 107.4 & Educación superior & 14.2 & 110.7 & 108.4 \\
\hline \multicolumn{8}{|c|}{ Información y telecomunicaciones } \\
\hline Hasta ESO & 3.2 & 97.9 & 66.7 & & & & \\
\hline Secundaria post. & 14.5 & 81.8 & 91.2 & & & & \\
\hline Educación superior & 82.3 & 103.7 & 103.7 & & & & \\
\hline
\end{tabular}

Fuente: Elaboración propia a partir de EPA.

Resultan no obstante más interesantes, para el objeto de este estudio, los indicadores de variación de la composición educativa. Las innovaciones relacionadas con la Revolución Industrial 4.0 son más intensivas en el uso de capital humano por lo que, en principio, los sectores más afectados tenderán a priorizar la contratación de personas con elevados niveles educativos. A nivel agregado, entre 2015 y 2020 la proporción de ocupados con educación superior en España creció, mientras que para los ocupados con estudios intermedios permaneció constante. La proporción de ocupados con reducidos niveles educativos cayó de forma significativa.

Por ramas de actividad, se observan muy distintas evoluciones. Se destacan, a continuación, las siguientes: información y telecomunicaciones; finanzas y seguros; y electricidad y gas. En el caso de información y telecomunicaciones, se observa una importante caída del peso relativo de las personas con un nivel educativo bajo y una reducción de los trabajadores con cualificaciones intermedias. El hecho de que el peso de las personas con estudios superiores crezca de forma modesta (un 3.7\%), una constatación aparentemente contraintuitiva -más aún si se pone en contacto con lo visto en la figura 4-, se debe a la ya muy elevada proporción de trabajadores con educación superior en esta actividad económica, en el año 2015. 
Como se ha visto previamente, otra actividad muy afectada por la Revolución Industrial 4.0 son las finanzas y seguros. En este caso, de forma similar a lo que sucede en el sector energético, se produce una caída en el peso relativo de los trabajadores sin educación superior. Los procesos de introducción de mecanismos de IA, que han revolucionado ambos sectores ${ }^{4}$, están detrás de esta tendencia. Reforzando el argumento anterior, tanto en sector energético como en el de las finanzas y en el de la información y telecomunicaciones, la destrucción de empleo resulta especialmente intensa, a partir de la crisis COVID-19, entre los trabajadores con un reducido nivel formativo.

Así pues, a lo largo de este capítulo se ha podido observar la existencia de un proceso de sustitución de trabajadores con un reducido nivel formativo por trabajadores con estudios superiores ${ }^{5}$. Si bien parte de esa sustitución se debe a la evolución demográfica (el nivel educativo medio de las cohortes más jóvenes es superior al de las más mayores, que se van retirando del mercado), ello no explica la totalidad de la transformación en la composición de las plantillas de las empresas. El argumento de la transición demográfica resulta todavía menos sostenible en aquellos sectores potencialmente más afectados por la Revolución Industrial 4.0. Se ha observado que, si bien el efecto de ésta sobre el volumen total de contratados resulta incierto, en todos ellos se ha producido un cambio acusado en el perfil formativo de sus trabajadores, acelerado a su vez por la crisis COVID-19. Dada la situación descrita, conviene revisar el grado de ajuste de la estructura formativa de la población española a la demanda de educación y competencias del nuevo mercado laboral. A ello se procede en el capítulo 4.

\section{La oferta laboral: formación de la población activa en España}

La implementación exitosa de la Revolución Industrial 4.0 depende no solamente de la dotación educativa de la población activa actual, sino también de la formación de los futuros trabajadores. En este capítulo se revisan algunos indicadores clave para la comprensión de la situación educativa de España. En el apartado 4.1 se revisa de forma sucinta la situación educativa de España respecto a los objetivos educativos marcados

\footnotetext{
${ }^{4}$ En el caso del sector energético, adicionalmente, se añade la presión por adaptarlo a los requisitos de la Agenda Verde Europea 2050. La implementación de nuevas fuentes energéticas también aumenta las necesidades formativas de sus trabajadores.

${ }^{5}$ Conviene no olvidar aquí la existencia de otros ejes de desigualdad, además del formativo, sobre los que la Revolución 4.0 también ha ejercido un importante impacto. Dolado et al. (2021) muestran de hecho que dicho impacto resulta heterogéneo por edad, sexo y tipo de contrato. Ahora bien, el análisis de estas cuestiones, relevantes, escapan del ámbito específico de este artículo, centrado en el encaje del perfil formativo de la población española en el nuevo mercado laboral.
} 
por dos estrategias clave de la Comisión Europea: la Estrategia UE-2020 ${ }^{6}$ y la Estrategia Education and Training (ET-2020). Ello da pie a la discusión de algunas de las fortalezas y debilidades de la estructura formativa española en el corto plazo (apartado 4.2).

\subsection{La formación de la población española}

Tanto las competencias cognitivas como las no cognitivas resultan relevantes para la adaptación de los trabajadores a innovaciones tecnológicas y en los procesos de producción. Estudios como Cabus et al. (2021) han señalado la importancia de las competencias no cognitivas, el liderazgo, la tolerancia al fracaso, la comunicación interpersonal, la capacidad de adaptación a cambios, la empatía o el trabajo en equipo, para el éxito de los trabajadores en el mercado laboral actual. Ahora bien, a pesar de reconocer la importancia de las competencias no cognitivas, este apartado se centra en la revisión de la dotación educativa, haciéndose mención a su vez a competencias cognitivas básicas, como las lectoras o numéricas, ya que resultan más fácilmente medibles $\mathrm{y}$, por tanto, se dispone de información al respecto. El nivel educativo de las personas, ya sea por su capacidad para trasmitir competencias y habilidades, ya sea por su rol de señalización de los trabajadores más capaces, está altamente correlacionado con el nivel de competencias cognitivas y es una variable determinante de la situación laboral de las personas. El caso español no es una excepción. Las personas con mayores niveles educativos tienen mayores tasas de actividad, ocupación, así como mayores niveles retributivos y de mejores condiciones laborales (Dolado et al., 2021).

La dotación educativa de la población española ha evolucionado rápidamente a lo largo de las últimas décadas (figura 6). De hecho, se ha realizado en un esfuerzo importante para cerrar la brecha formativa respecto a los países de su entorno. Durante las primeras décadas del siglo XXI la proporción de población con reducidos niveles educativos ha descendido en 25 puntos porcentuales y el porcentaje de adultos con estudios superiores ha pasado del $21,1 \%$ al $38,6 \%$. La penúltima barra de la figura 8 muestra claramente que la dotación formativa actual de España tiene una forma de "reloj de arena", con un número limitado de personas que ha completado estudios de nivel intermedio -bachillerato y ciclos formativos-. Se trata de una estructura formativa que diverge claramente de la situación media en Europa, donde los estudios de nivel intermedio tienen un peso muy superior y la proporción de personas con reducidos niveles de estudios es pequeña.

${ }^{6}$ La Estrategia Europa 2020 o Estrategia UE-2020 arranca en el año 2010 estableciendo una serie de objetivos, también en el área educativa, para la consecución de un crecimiento inteligente, sostenible e inclusivo en el año 2020. La consecución de dichos objetivos debía conducir a incrementos en la productividad en un nuevo modelo económico más competitivo y sostenible.

Araucaria. Revista Iberoamericana de Filosofia, Política, Humanidades y Relaciones Internacionales, año $23, \mathrm{n}^{\circ} 47$. Segundo cuatrimestre de 2021. Pp. 479-505. ISSN 1575-6823 e-ISSN 2340-2199 https://dx.doi.org/10.12795/araucaria.2021.i47.21 
Figura 6. Evolución del nivel formativo de la población de entre 25 y 64 años en España y la UE-15 entre 1999 y 2019. Porcentajes.

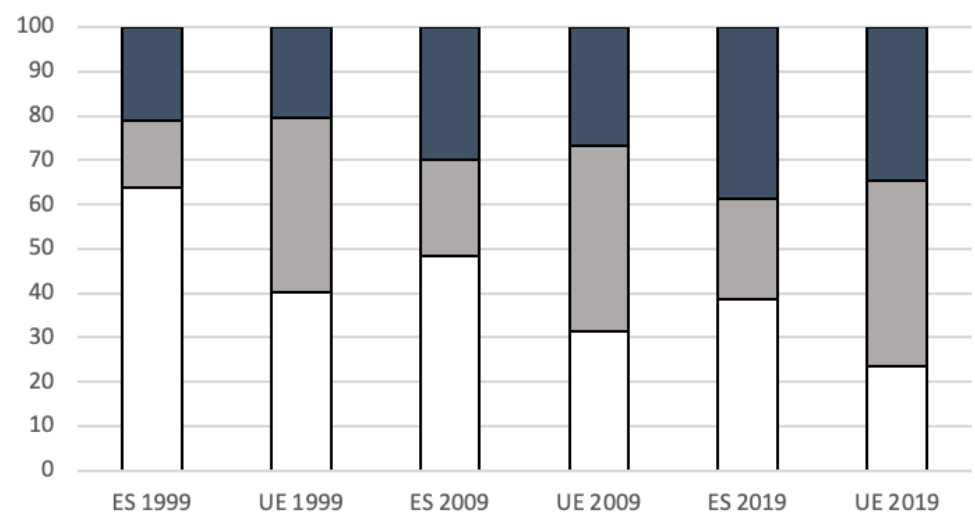

口ISCED 0-2 ISSCED 3-4 ISCED 5-8

Fuente: Elaboración propia a partir de Eurostat.

Nota: UE hace referencia a UE-15. ISCED 0-2: hasta educación secundaria obligatoria. ISCED 3-4: educación secundaria postobligatoria. ISCED 5-8: educación superior.

Este rápido crecimiento en la dotación educativa no se ha producido de forma homogénea entre la población, sino que obedece claramente a un relevo generacional. Las generaciones más jóvenes tienen unos niveles educativos muy superiores a las cohortes anteriores. Ello tiene una vertiente positiva y, otra, negativa. La vertiente positiva consiste en el hecho de que durante los próximos años la dotación educativa media de la población activa seguirá creciendo. Por ejemplo, según INE, en el año 2019, la proporción de personas de entre 25 y 34 años de edad con estudios superiores era del 46,5\%, siendo esa proporción del $26,7 \%$ para las personas de entre 55 y 64 años de edad. Estas personas, con mayores niveles educativos, deberían encontrar acomodo relativamente más fácilmente en el mercado laboral. No obstante, la brecha generacional en términos formativos supone un reto en el corto y medio plazo: la creciente dificultad de las personas más mayores -así como de las personas jóvenes con bajos niveles de estudio- para acceder a un mercado laboral cambiante y que demanda a sus trabajadores un mayor nivel de competencias, tanto cognitivas como no cognitivas.

La revisión del grado de consecución de los objetivos ${ }^{7}$ educativos fijados

\footnotetext{
${ }^{7}$ La Comisión Europea está en proceso de revisión y actualización de estos objetivos e indicadores. En concreto, plantea el establecimiento de los siguientes objetivos a alcanzar en el 2030: el 98\% de Segundo cuatrimestre de 2021. Pp. 479-505. ISSN 1575-6823 e-ISSN 2340-2199 https://dx.doi.org/10.12795/araucaria.2021.i47.21
} 
por las estrategias UE-2020 y ET-2020 permite una aproximación integral y sintética a la situación educativa de los países. El grado de cumplimiento de España respecto a los umbrales a alcanzar establecidos por las estrategias UE2020 (para los indicadores de abandono escolar prematuro y tasa de graduación en educación superior) y ET-2020 (los indicadores restantes ${ }^{8}$ ) se presentan en la figura 7.

Figura 7. Grado de consecución de los objetivos educativos establecidos en las estrategias Europa 2020 y Education and Training 2020. España, 20122020 .

\begin{tabular}{|c|c|c|c|}
\hline & $\begin{array}{l}\text { Objetivo } \\
\text { UE 2020 }\end{array}$ & 2012 & 2020 \\
\hline $\begin{array}{l}\text { Tasa de escolarización en educación } \\
\text { infantil a los } 5 \text { años }\end{array}$ & $95 \%$ & $\begin{array}{r}97,2 \% \\
(93,3 \%) \\
\end{array}$ & $\begin{array}{l}97,9 \% * \\
(93,8 \%) \\
\end{array}$ \\
\hline $\begin{array}{l}\text { Porcentaje de alumnado de } 15 \text { años } \\
\text { con un reducido nivel de competen- } \\
\text { cias lectoras }\end{array}$ & $15 \%$ & $\begin{array}{r}18,3 \% \\
(17,8 \%)\end{array}$ & $\begin{array}{r}23,0 \% * * \\
(22,5 \%)\end{array}$ \\
\hline $\begin{array}{l}\text { Porcentaje de alumnado de } 15 \text { años } \\
\text { con un reducido nivel de competen- } \\
\text { cias matemáticas }\end{array}$ & $15 \%$ & $\begin{array}{r}23,6 \% \\
(22,1 \%)\end{array}$ & $\begin{array}{r}24,7 \% * * \\
(22,9 \%)\end{array}$ \\
\hline $\begin{array}{l}\text { Porcentaje de alumnado de } 15 \text { años } \\
\text { con un reducido nivel de competen- } \\
\text { cias científicas }\end{array}$ & $15 \%$ & $\begin{array}{r}15,7 \% \\
(16,6 \%)\end{array}$ & $\begin{array}{r}21,3 \% * * \\
(22,3 \%)\end{array}$ \\
\hline Tasa de abandono escolar prematuro & $\begin{array}{r}15 \% \\
(10 \%) \\
\end{array}$ & $\begin{array}{r}24,7 \% \\
(12,6 \%) \\
\end{array}$ & $\begin{array}{r}16 \% \\
(10,1 \%) \\
\end{array}$ \\
\hline $\begin{array}{l}\text { Porcentaje de población de } 30 \\
\text { a } 34 \text { años graduada en estudios } \\
\text { superiores }\end{array}$ & $\begin{array}{r}44 \% \\
(40 \%)\end{array}$ & $\begin{array}{r}41,5 \% \\
(34,5 \%)\end{array}$ & $\begin{array}{r}44,8 \% \\
(40,9 \%)\end{array}$ \\
\hline $\begin{array}{l}\text { Movilidad educativa: Graduados de } \\
\text { nivel superior (ISCED 5-8) que ob- } \\
\text { tienen el título en el extranjero }\end{array}$ & $20 \%$ & & $\begin{array}{r}2,2 \% * * \\
(4,3 \%)\end{array}$ \\
\hline
\end{tabular}

niños de 3 a 5 años debe estar escolarizado; el abandono escolar prematuro debe ser inferior al 9\%; el porcentaje de graduados en educación superior de entre 30 y 34 años, del 50\%; se mantiene el objetivo en cuanto al nivel de competencias en matemáticas, lectura y ciencias; y el 50\% de los adultos debe participar anualmente en actividades de formación.

${ }^{8}$ La Estrategia ET-2020 también incluía un objetivo relativo a la movilidad del alumnado de formación profesional. Lamentablemente, las limitaciones en los datos han impedido un seguimiento adecuado de este objetivo.

Araucaria. Revista Iberoamericana de Filosofia, Política, Humanidades y Relaciones Internacionales, año $23, \mathrm{n}^{\circ} 47$. Segundo cuatrimestre de 2021. Pp. 479-505. ISSN 1575-6823 e-ISSN 2340-2199 https://dx.doi.org/10.12795/araucaria.2021.i47.21 


\begin{tabular}{|l|r|r|r|}
\hline $\begin{array}{l}\text { Movilidad educativa: Graduados de } \\
\text { nivel superior (ISCED 5-8) que han } \\
\text { cursado créditos en el extranjero }\end{array}$ & $20 \%$ & $\begin{array}{r}7,7 \% * * \\
(9,1 \%)\end{array}$ \\
\hline $\begin{array}{l}\text { Porcentaje de población adulta (25- } \\
64 \text { años) en actividades formativas } \\
(4 \text { semanas previas a la entrevista) }\end{array}$ & $15 \%$ & $\begin{array}{r}10,7 \% \\
(9,0 \%)\end{array}$ & $\begin{array}{r}10,6 \% * \\
(10,8 \%)\end{array}$ \\
\hline $\begin{array}{l}\text { Tasa de ocupación de las personas de } \\
20-34 \text { años con un nivel formativo } \\
\text { mínimo de educación secundaria } \\
\text { superior que se graduaron en los 1 a } \\
3 \text { años previos }\end{array}$ & $82 \%$ & $\begin{array}{r}60,4 \% \\
(73,8 \%)\end{array}$ & $\begin{array}{r}66,0 \% \\
(78,0 \%)\end{array}$ \\
\hline
\end{tabular}

Fuente: Elaboración propia a partir de Eurostat y Comisión Europea (2020).

Nota: Entre paréntesis, media de la Unión Europea (27 países). *, datos de 2019. **, datos de 2018.

España presenta una situación óptima en el primero de los indicadores: ha alcanzado prácticamente la universalización de la educación infantil. Se trata de uno de los tipos de inversión educativa con un mayor impacto positivo sobre la trayectoria académica y laboral de las personas (Cunha y Heckman, 2010).

Los siguientes tres indicadores se refieren al porcentaje de alumnos de 15 años que obtuvieron un muy bajo rendimiento en las pruebas correspondientes a la evaluación internacional Programme International Student Assessment (PISA), de la OCDE. Situarse por debajo del nivel 2 de competencias en las pruebas de PISA está asociado a un mayor riesgo de abandono escolar prematuro y a dificultades en la integración socioeconómica posterior (Schleicher, 2007). Tal y como se observa en la figura 7, la proporción de jóvenes españoles con un reducido nivel de competencias se sitúa por encima de la media de la UE y del umbral para el año 2020 (15\%), para las tres competencias analizadas. Por otro lado, si bien no se muestra en la figura 7, la proporción de alumnos con muy elevados niveles de competencias es, comparativamente, reducido. De hecho, se observan patrones similares, a la edad de 9/10 años, en las evaluaciones Trends in International Mathematics and Science Study (TIMSS) y Progress in International Reading Literacy Study (PIRLS), elaborados porInternational Association for the Evaluation of Educational Achievement (IEA).

El abandono escolar prematuro -proporción de personas de entre 18 y 24 años de edad que no ha concluido estudios secundarios postobligatorios- es el principal problema del sistema educativo español. A pesar de haberse pasado de una tasa de prácticamente el $30 \%$ a inicios de la década de 2010 al 16\% en 2020, sigue siendo muy elevada. Las personas con muy reducidos niveles educativos tienen menores tasas de actividad, mayores tasas de desempleo, 
ocupan puestos con menores niveles retributivos y con peores condiciones laborales y dependen en un mayor grado de las prestaciones sociales. Se trata por tanto de un colectivo especialmente vulnerable, vulnerabilidad que se verá acusada ante la creciente demanda de nuevas competencias en el mercado laboral. Se trata de un fenómeno más acusado entre los hombres $-20,2 \%$, frente al $11,6 \%$, para las mujeres-y con una distribución territorial muy desigual. Por ejemplo, Asturias o el País Vasco se sitúan muy por debajo incluso de la media de la UE, mientras Andalucía y Baleares más que duplican dicha media.

Los siguientes tres indicadores de la figura 7 se centran en los niveles educativos superiores. Los dos primeros se refieren a la movilidad del alumnado; el siguiente, a la tasa de graduación universitaria. La movilidad de los alumnos universitarios españoles resulta reducida, si bien España es uno de los principales receptores de alumnos extranjeros. El tercer indicador muestra que el porcentaje de jóvenes españoles que concluye estudios superiores $(44,8 \%)$ es elevado, en términos europeos. Ello supone una buena noticia para la implementación de innovaciones y nuevas tecnologías. Naturalmente, resulta imprescindible conocer qué tipo de formación concluyen estas personas, ya que dentro del nivel educativo superior existen numerosas titulaciones de muy distinto perfil y ajuste a las necesidades generadas por la Revolución 4.0. En el año 2020, el 2,2\% de los españoles (3\% de los hombres; $1,3 \%$ de las mujeres) de entre 20 y 29 años de edad se habían graduado en educación superior en áreas STEM, manufacturas y construcción -frente al 2\% de media de la UE-27-, consideradas estratégicas para la implementación de los cambios productivos y organizativos asociados a la Revolución Industrial 4.0.

La calidad de la educación, y no solo su cantidad, resulta tanto o más relevante en el mercado laboral. El Programme for the International Assessment of Adult Competencies (PIAAC), de la OCDE, es una de las pocas fuentes disponibles que miden el nivel de competencias de las personas adultas. Puede entenderse ese nivel de competencias como una proxy de la calidad formativa. Pues bien, en dicha evaluación, la población española de entre 16 y 65 años es la que tiene el nivel más reducido de competencias numéricas, y el segundo peor en competencias lectoras, de toda la OCDE (OCDE, 2013). Ello es así a pesar de que, en España, el proceso de catch-up generacional (la brecha de resultados entre la cohorte más mayor y la cohorte más joven del estudio) ha sido la segunda más intensa de la OCDE, durante estos últimos treinta años, tras Corea del Sur. Adicionalmente, la revisión de la información disponible en Eurostat sobre el nivel de competencias digitales y en lenguas extranjeras, obtenida respectivamente a partir de Digital Competence Framework y de la Adult Education Survey, permite afirmar que la población española dispone de un nivel de competencias digitales similar a la media europea pero un nivel de conocimiento de lenguas extranjeras deficiente. 
Volviendo a la figura 7, la falta de cualificación o de competencias adquiridas durante el período formativo podría compensarse mediante la participación en actividades de formación (educación formal, no formal e informal) en edad adulta. La formación continua tiene el potencial para adaptar a los trabajadores a nuevos procesos de producción y mejoras organizativas. España se encuentra en una situación similar a la de la media europea (10,6\% por $10,8 \%$ de la UE-27), por debajo del umbral a alcanzar en 2020 (15\%). De hecho, la situación de España en términos de participación en actividades de formación continua ha permanecido estancada durante la década de $2010(10,7 \%$, en $2012 ; 10,6 \%$ en 2019). Resulta asimismo destacable que, en España, las personas con menores niveles educativos (con ESO como máximo), son uno de los colectivos que menos participan (sólo el 3,5\%, en 2019 -frente al 18,2\% de las personas con estudios superiores), cuando se trata de uno de los colectivos que más podrían beneficiarse de la participación en estas actividades formativas.

Por último (fila inferior de la figura 7), la Estrategia ET-2020 establece como objetivo alcanzar una tasa de ocupación, para los jóvenes cuya educación sea igual o mayor a secundaria superior y que se graduaron entre los 12 y 36 meses previos, superior al $82 \%$. Este indicador ya no se centra solo en factores de oferta laboral (educación, en este caso) sino en su interacción con factores de demanda laboral tales como el grado de apertura al comercio internacional, la composición sectorial de la economía o las innovaciones tecnológicas. La situación de España aquí resulta especialmente preocupante, ya que en el año 2020 se encuentra (66\%) muy alejada de la media europea (78\%). Tasas elevadas de desempleo juvenil llevan a una mayor dependencia de prestaciones públicas, trayectorias laborales más inestables y la obsolescencia de sus conocimientos y habilidades.

\subsection{Fortalezas y debilidades de la estructura educativa frente a la Revolu- ción Industrial 4.0}

En el capítulo 3 se ha visto que Revolución Industrial 4.0 penaliza a las personas con reducidos niveles formativos y recompensa a los trabajadores más cualificados y cuyas competencias mejor se adaptan a los procesos de robotización y automatización de la actividad. En el apartado anterior se ha realizado una revisión panorámica de la situación educativa en España. Ello da pie a la presentación de los puntos que pueden ser considerados como fortalezas y como debilidades de la estructura formativa española, en cuanto a su grado de ajuste a las nuevas necesidades del mercado laboral. 
Entre las fortalezas pueden destacarse:

- Elevadas tasas de escolarización infantil.

- Fuerte caída en la tasa de abandono escolar prematuro.

- Introducción con resultados prometedores de la formación profesional dual.

- Elevado número de graduados universitarios.

- De entre aquéllos, elevada proporción de graduados en áreas STEM.

- Elevado número de titulados en doctorado.

- Población adulta con un nivel de competencias digitales equiparable a la media UE.

Entre las debilidades, se señalan las siguientes:

- Bajo nivel de competencias numéricas, lectoras y científicas en los niveles educativos obligatorios. Ello condiciona el resto del proceso formativo.

- A pesar de la importante reducción en las tasas de abandono escolar prematuro, todavía se tardará años en cerrar la brecha con el resto de países de la UE.

- Bajo nivel de competencias lectoras, numéricas y de idiomas extranjeros de los adultos. De forma similar a lo observado para las tasas de abandono escolar prematuro, la velocidad del proceso de catch-up de las nuevas generaciones no resulta suficiente.

- Potencial escasez de técnicos cualificados, como consecuencia de las bajas tasas de graduación en estudios vocacionales. Ello es así, a pesar del aumento experimentado durante la segunda mitad de la década de 2010 en el número de matriculados en ciclos de formación de grado superior. A pesar de la introducción de la modalidad dual, el número de alumnos que la siguen sigue siendo muy reducido (en el curso 2018/19, sólo el $0,7 \%, 2,9 \%$ y 4,6\% de los alumnos de formación profesional básica, media y superior).

- Reducida participación en actividades de formación continua.

\section{Discusión y conclusiones}

En este artículo se ha descrito la existencia de importantes cambios en el mercado laboral español, como consecuencia de su adaptación a los cambios asociados a la Revolución Industrial 4.0. Se ha observado que, en primer lugar, el impacto sobre el nivel de empleo varía por 
ramas de actividad. En segundo lugar, se ha confirmado el cambio en la composición formativa de los trabajadores. En tercer lugar, que el proceso de sustitución de trabajadores poco cualificados por otros con elevados niveles formativos se aceleró con la crisis COVID-19, especialmente en los sectores más susceptibles de ser afectados por procesos de robotización y digitalización.

La rapidez en los cambios en la demanda laboral, que pasa a demandar nuevos perfiles más formados y más flexibles, puede generar importantes desequilibrios en el mercado laboral, si la dotación educativa y competencial de la oferta no se ajusta a los nuevos requisitos. Se han identificado una serie de fortalezas y debilidades, tanto a corto como a largo plazo, de la dotación educativa de la población española para afrontar los retos planteados por la Revolución Industrial 4.0. Si bien se reconocen sus limitaciones metodológicas, la combinación de lo observado en los capítulos 3 y 4 permite la elaboración de líneas generales de intervención en materia educativa y de formación para la implementación exitosa de las innovaciones asociadas a la Revolución Industrial 4.0.

En primer lugar, el reto prioritario consiste en reducir los niveles de abandono escolar prematuro. En segundo lugar, y relacionado con la recomendación anterior, conviene aumentar la proporción de población española que cursa estudios vocacionales. La falta de técnicos cualificados puede convertirse en un cuello de botella para la implementación de nuevas tecnologías.

En tercer lugar, la consecución de las primeras dos recomendaciones se verá favorecida si se produce, en general, una mejora en los niveles de competencias básicas del alumnado. Resulta especialmente prioritario aumentar el nivel de competencias numéricas, altamente demandadas por el mercado laboral y en las que la población española puntúa muy bajo, así como las digitales, si bien el alumnado joven español dispone de un nivel más elevado en estas últimas.

En cuarto lugar, dada la velocidad en los cambios tecnológicos y organizativos, resulta recomendable explorar nuevas formas de cooperación entre las empresas y el sector educativo y formativo, de forma que exista retroalimentación constante entre ambos. Ejemplos de ello serían la extensión de la formación profesional dual, la implementación de programas educación superior dual o el diseño de nuevas formas de colaboración universidadempresa.

En quinto lugar, conviene flexibilizar los planes de estudios en los niveles postobligatorios. Los objetivos son, al menos, dos: primero, evitar el abandono de estudios y, segundo, permitir que los alumnos sean capaces de ajustar mejor sus trayectorias formativas a las necesidades del mercado laboral. La Revolución Industrial 4.0 ha difuminado las fronteras 
tradicionales entre ciencias, haciendo necesario el conocimiento transversal entre disciplinas.

Por ello, debe establecerse canales que faciliten la adaptación de los trabajadores en la transición. Así, en sexto lugar, debe mejorarse la formación en el puesto de trabajo. La intensificación de la formación durante la vida adulta debería facilitar la adaptación progresiva de los trabajadores a los cambios en el sistema productivo. Tal y como se ha visto, la situación en España, en esta cuestión, resulta insuficiente. La velocidad a la que se implementan los cambios asociados a la Revolución Industrial 4.0 parecen demandar un mayor protagonismo de la formación no formal e informal, dado su mayor adaptabilidad al cambio -frente a la relativa rigidez de la formación formal-.

Así pues, el éxito de la implementación de la Revolución Industrial 4.0 en España dependerá en buena medida de su capacidad para abastecer al tejido productivo de trabajadores altamente cualificados, así como de la capacidad de las empresas para interaccionar con el sistema educativo y facilitar a sus trabajadores el acceso a actividades de formación dentro o fuera del centro de trabajo. Para concluir, vale la pena apuntar un último riesgo, vinculado a los cambios tecnológicos asociados a la Revolución Industrial 4.0: para ciertos perfiles laborales, cada vez resulta más sencillo el desempeño del trabajo a distancia, por lo que la contratación de trabajadores residentes en el extranjero resulta cada vez más plausible, sencilla y barata. Acometer reformas en el sistema formativo resulta, por tanto, urgente, tanto para facilitar el potencial de crecimiento económico de la Revolución Industrial 4.0, como para minimizar sus costes sociales.

\section{Referencias:}

Acemoglu, D., \& Restrepo, P. (2020). Robots and jobs: Evidence from US labor markets. Journal of Political Economy, 128(6): 2188-2244.

Aghion, P., Jones, B. F., \& Jones, C. I. (2019). 9. Artificial Intelligence and Economic Growth (pp. 237-290). En The Economics of Artificial Intelligence: An Agenda. Chicago: University of Chicago Press.

Arntz, M., Gregory, T., \& Zierahn, U. (2017). Revisiting the risk of automation. Economics Letters, 159: 157-160.

Autor, D. \& Salomons, A. (2017). Robocalypse Now: Does Productivity Growth Threaten Employment? European Central Bank Sintra Forum Conference Paper, junio.

Berg, A., Buffie, E. F., \& Zanna, L. F. (2018). Should we fear the robot revolution? (The correct answer is yes). Journal of Monetary Economics, 97: 117-148.

Braña, F. J. (2019). A fourth industrial revolution? Digital transformation, labor and work organization: a view from Spain. Journal of Industrial and Business Economics, 46(3): 415-430.

Brynjolfsson, E., \& Mitchell, T. (2017). What can machine learning do? Workforce implications. Science, 358(6370): 1530-1534. 
Bughin, J., Hazan, E., Ramaswamy, S., Chui, M., Allas, T., Dahlstrom, P., \& Trench, M. (2017). Artificial intelligence: The next digital frontier? McKinsey Glob Institute Discussion Paper, June.

Cabus, S., Napierala, J., \& Carretero, S. (2021). The returns to non-cognitive skills: A meta-analysis. JRC Working Papers Series on Labour, Education and Technology, No. 2021/06.

Caselli, F., \& Manning, A. (2019). Robot arithmetic: new technology and wages. American Economic Review: Insights, 1(1): 1-12.

CEDEFOP (2018). Insights into skill shortages and skill mismatch Learning from Cedefop's European skills and jobs survey. Luxembourg: Publications Office.

Choi, Á. \& Calero, J. (2018). El capital humano en los procesos de automatización: una primera aproximación al caso español. Cuadernos Económicos del ICE, 95: 13-32C.

Comisión Europea (2020). Monitor de la Educación y de la Formación de 2020. España. Luxemburgo: Oficina de Publicaciones de la Unión Europea.

Cowen, T. (2019). Neglected open questions in the economics of artificial intelligence (pp. 391-395). En The Economics of Artificial Intelligence: An Agenda. Chicago: University of Chicago Press.

Cunha, F. \& Heckman, J.J. (2010). Investing in Our Young People. NBER Working Paper Series, 16201.

Dauth, W., Findeisen, S., Jens, S., \& Woessner, N. (2017). German Robots-The Impact of Industrial Robots on Workers. CEPR Discussion Papers, 12306.

Decker, M., Fischer, M., \& Ott, I. (2017). Service Robotics and Human Labor: A first technology assessment of substitution and cooperation. Robotics and Autonomous Systems, 87: 348-354.

Dolado, J. J., Felgueroso, F., \& Jimeno, J. F. (2021). Past, present and future of the Spanish labour market: when the pandemic meets the megatrends. Applied Economic Analysis, 29(85): 21-41.

Doménech, R., García, J. R., Montañez, M., \& Neut, A. (2018). How vulnerable is Spanish employment to the digital revolution? BBVA Research Working Paper.

Eichhorst, W. (2015). Do we have to be afraid of the future world of work? IZA Policy Paper, 102.

Frey, C. B., \& Osborne, M. A. (2017). The future of employment: How susceptible are jobs to computerisation? Technological Forecasting and Social Change, 114: 254-280.

Gibbs, M. (2017). How is new technology changing job design? IZA World of Labor, 344.

González-Páramo, J. M. (2018). Cuarta revolución industrial, empleo y estado de bienestar. En Anales de la Real Academia de Ciencias Morales y Políticas (pp. 89113). Madrid: Ministerio de Justicia.

Hutter, C., \& Weber, E. (2017). The effects of skill-biased technical change on productivity flattening and hours worked. IAB-Discussion Paper, 32/2017.

Kuzmenko, O., \& Roienko, V. (2017). Nowcasting income inequality in the context of the Fourth Industrial Revolution. SocioEconomic Challenges, 1(1): 5-12.

Korinek, A., \& Stiglitz, J. E. (2019). Artificial Intelligence and Its Implications for Income Distribution and Unemployment (pp. 349-390). En The Economics of Artificial Intelligence: An Agenda. Chicago: University of Chicago Press.

Levy, F. (2018). Computers and populism: artificial intelligence, jobs, and politics in the near term. Oxford Review of Economic Policy, 34(3): 393-417. 
Lane, M. \& Saint-Martin, A. (2021). The impact of Artificial Intelligence on the labour market: What do we know so far? OECD Social, Employment and Migration Working Papers, 256.

Lladós-Masllorens, J. (2019). Surfing the Waves of Digital Automation in Spanish Labor Market (pp. 451-458). En The International Research \& Innovation Forum. Springer, Cham.

Mokyr, J. (2018). The past and the future of innovation: Some lessons from economic history. Explorations in Economic History, 69: 13-26.

Morikawa, M. (2017). Who are afraid of losing their jobs to artificial intelligence and robots? Evidence from a survey. GLO Discussion Paper, 71.

OECD (2013). OECD Skills Outlook 2013: First Results from the Survey of Adult Skills. París: OCDE.

OCDE (2019). The Future of Work. OECD Employment Outlook 2019. Paris: OCDE.

Peco, P. P. (2017). Nuevos empleos, nuevas habilidades: ¿estamos preparando el talento para la Cuarta Revolución Industrial? Información Comercial Española, ICE: Revista de Economía, 898: 59-72.

Raj, M. \& Seamans, R. (2019). AI, labor, productivity, and the need for firm-level data (pp.553-565). En Economics of Artificial Intelligence. Chicago: University of Chicago.

Sachs, J. D., Benzell, S. G., \& LaGarda, G. (2015). Robots: Curse or blessing? A basic framework. NBER Working Papers, 21091.

Schmidpeter, B. \& Winter-Ebmer, R. (2018). How Do Automation and Offshorability Influence Unemployment Duration and Subsequent Job Quality? IZA Discussion Paper, 11736.

Vivarelli, M. (2014). Innovation, employment and skills in advanced and developing countries: A survey of economic literature. Journal of Economic Issues, 48(1): 123154.

World Economic Forum. (2016). The future of jobs: Employment, skills and workforce strategy for the fourth industrial revolution. Ginebra: WEF. 
